\title{
El feble arrelament del populisme a Espanya
}

\author{
Astrid Barrio \\ UNIVERSITAT DE VALÈNCIA \\ astrid.barriolauv.es
}

Rebut: 22/05/2019

Acceptat: 09/03/2020

\section{RESUM}

Aquest article analitza les raons per les quals a Espanya no ha arrelat el populisme malgrat donar-se moltes de les condicions associades al sorgiment i creixement d'aquest corrent polític - una profunda crisi econòmica que es va iniciar l'any 2008 i una crisi política vinculada als escàndols de corrupció que afectaven els principals partits del sistema. Al nostre país l'extrema dreta tradicional és molt dèbil. A més, no podem considerar els nous partits com Podemos o Ciudadanos com a populistes; i Vox, tot i que compleix tots els requisits d'un partit de dreta radical, es diferencia de la seua família política en el fet que no és populista. En aquest article s'argumenta que aquesta absència de populisme s'explica, sobretot, per la preeminència de les fractures esquerra-dreta i nacional, característiques polítiques tradicionals entorn de les quals s'articula la competència política a Espanya.

Paraules clau: populisme, extrema dreta, dreta radical, Podemos, Ciudadanos, Vox.

ABSTRACT. The Weakness of Populism in Spain

This paper analyses why Populism has failed to take root in Spain despite a 'soil' that has favoured its seeding and growth elsewhere. At first sight, Spain seems to provide the conditions in which Populism can thrive: a deep economic crisis (which began with the financial meltdown in 2008) and a succession of corruption scandals affecting all the main political parties. Even so, Populism has failed to gain a hold in Spain. The traditional Far Right is very weak, and new parties such as Podemos and Ciudadanos cannot be considered Populist. While Vox displays all the features of a radical right-wing party, it is one from which Populism is absent. We argue that the lack of Populism in Spain can mainly be explained by the highly fractured nature of the country's politics, with left-right and national fault lines shaping how political competition plays out in the nation.

Keywords: populism, Far Right, Radical Right, Podemos, Ciudadanos, Vox.

\author{
SUMARI \\ Introducció \\ Què és el populisme, com sorgeix i es consolida? \\ La limitada presència de partits populistes de dreta radical \\ Els nous partits: Podemos i Ciudadanos \\ Vox, un partit de dreta radical no populista \\ Consideracions finals \\ Referències bibliogràfiques
}

Autor per a correspondència / Corresponding author: Astrid Barrio López. Departament de Dret Constitucional, Ciència Política i de l'Administració. Facultat de Dret. Avda. dels Tarongers s/n, 46022 València (Espanya).

Suggeriment de citació / Suggested citation: Barrio, A. (2020). El feble arrelament del populisme a Espanya. Debats. Revista de cultura, poder i societat, 134(1), 233-246. DOI: http://doi.org/10.28939/iam.debats.134-1.14 


\section{INTRODUCCIÓ}

Un dels fenòmens polítics recents més destacats al món occidental —encara que no només en aquest espai geogràfic - ha sigut l'emergència del populisme, una tendència de la qual molt poques democràcies consolidades semblen haver escapat. El populisme s'ha estés tant que s'ha arribat a afirmar que les democràcies occidentals sense populismes forts constitueixen més una excepció que la norma (Marzouki, McDonnel i Rey, 2016).

L'objectiu d'aquest article és mostrar que a Espanya, on s'han donat moltes de les condicions associades al sorgiment i creixement del populisme, aquest corrent polític no ha arrelat i segueix sent una excepció (Barrio, 2017a). Tot i que la crisi econòmica iniciada l'any 2008 i la crisi política vinculada als escàndols de corrupció dels principals partits del sistema van propiciar a partir de 2014 l'emergència de nous partits com Podemos i Vox, així com l'extensió de Ciudadanos al conjunt de la política espanyola, cap d'aquests partits pot considerar-se populista en essència. Les dificultats del populisme per a assentar-se s'explicarien, sobretot, pel predomini de l'eix esquerra-dreta i de la qüestió nacional, enteses com les principals fractures polítiques entorn de les quals s'articula la política a Espanya.

L'article s'estructura en quatre apartats. En el primer es delimita el concepte de populisme i s'exposen les condicions que en propicien l'aparició i en condicionen el desenvolupament. En el segon s'expliquen les raons de la presència limitada de la dreta radical a Espanya fins a l'emergència de Vox. En el tercer s'exposa per què Ciudadanos i Podemos, partits de recent creació, no poden ser considerats partits populistes. Finalment, en el quart, es raonen els motius pels quals Vox és un partit de dreta radical però no específicament populista.

\section{DEFINICIÓ, SORGIMENT I CONSOLIDACIÓ}

La paraula populisme es troba plenament implantada en el llenguatge ordinari i té una connotació clara- ment pejorativa. Es considera un concepte tan despectiu que les organitzacions o els líders qualificats com a populistes rarament es reconeixen com a tals. A més, ha sigut un concepte àmpliament utilitzat per referir-se a una gran diversitat de moviments, partits i idees en diferents espais geogràfics i en diferents etapes històriques. En conseqüència, la dificultat per construir una definició que englobe una pluralitat semblant no és extraordinària (Canovan, 1982), malgrat que els acadèmics no hagen cessat en l'obstinació d'elaborar una teoria unificada.

El fenomen s'ha abordat des de diferents aproximacions i disciplines. Totes tenen en comú l'assumpció que el populisme té una naturalesa dualista com a resultat de la contraposició entre el poble — de naturalesa virtuosa - i una elit dirigent —sempre corrupta. Més enllà d'aquest mínim comú denominador, el debat se situa, d'acord amb la distinció proposada per Moffit i Tormey (2014), al voltant dels qui consideren que el populisme és una ideologia, els qui el perceben com una lògica, els qui sostenen que és un discurs o un estil de comunicació, i els qui creuen que és una estratègia o una modalitat organitzativa.

El populisme pot entendre's com una ideologia en el sentit que conté un conjunt coherent d'idees sobre com organitzar la societat i com exercir el poder. No obstant això, més que una ideologia en sentit estricte, se sol assumir que el populisme és una ideologia prima (Stanley, 2008) que necessita mesclar-se amb altres ideologies considerades gruixudes o amb altres ideologies primes — com el nacionalisme. En canvi, la concepció del populisme com una lògica pretén allunyar-se de les disputes semàntiques i se centra en la dimensió ontològica del fenomen. En aquesta línia es troba Laclau (2005), qui considera que el populisme és la lògica que estructura la vida política i s'emmarca en la lluita per l'hegemonia. D'aquesta manera, un moviment, partit o líder no ha de considerar-se populista per representar continguts clarament identificables com a tals en la ideologia i les polítiques, sinó perquè mostra una lògica particular en la manera d'articular-los. La 
consideració del populisme com un patró discursiu o un estil de comunicació posa el focus en la idea del poble com a ésser virtuós que ha sigut traït per unes elits corruptes a les quals cal enderrocar, i fa d'aquesta idea el principal argument comunicatiu. Per acabar, cal destacar l'enfocament que percep el populisme com una estratègia o una forma d'organització per mitjà de la qual els líders personalistes proven d'exercir el poder a través del suport directe, immediat i no institucionalitzat ni organitzat dels seus seguidors. Amb l'objectiu de superar les limitacions que presenten les diferents aproximacions, Moffit i Torney (2014) sostenen que el populisme ha de considerar-se, per damunt de tot, un estil polític, que estaria caracteritzat per l'apel-lació al poble com a portador de la sobirania i per l'oposició respecte d'una elit corrupta. També per l'assumpció que hi ha una situació d'emergència derivada de la percepció de crisi o d'amenaça. I finalment, per l'ús sistemàtic de les males maneres, és a dir, de la incorrecció política.

Encara que es detecten nombroses discrepàncies quant a l'enfocament, la definició de Mudde (2004: 543) del populisme com una ideologia prima ha sigut àmpliament acceptada. Segons aquest autor, el populisme és «una ideologia prima que considera que la societat es divideix, en última instancia, en dos grups homogenis i antagònics, "la gent pura" i "l'elit corrupta"; i que argumenta que la política hauria de ser una expressió de la volonté générale [voluntat general] de la gent». Aquesta definició recull bona part de les aportacions de les distintes aproximacions i conté, com han apuntat Kriesi i Pappas (2015), quatre elements fonamentals que cal tenir en compte: l'acceptació del fet que hi ha dos grups homogenis, el poble i l'elit; l'existència de relacions antagòniques entre ells; una concepció del poble com a sobirà; i una perspectiva maniquea per mitjà de la qual una concepció positiva del poble s'oposa a una elit que és denigrada.

Però a més, Pappas (2014) i Kriesi i Pappas (2015) afegeixen que el que caracteritza el populisme és una concepció il-liberal de la democràcia (Zakaria,
1997). Aquesta concepció es basa, en primer lloc, en l'assumpció literal de la idea de govern del poble i en el rebuig als controls clàssics i als equilibris liberals. En segon lloc, en l'hostilitat cap als intermediaris i en la preferència per una vinculació directa de les masses amb els líders que els porta a optar per mecanismes de democràcia participativa. Finalment, es recolza en la idea de l'existència d'una voluntat monolítica del poble que no deixa espai al pluralisme. I és precisament d'aquesta concepció monolítica del poble d'on deriva no únicament l'antagonisme cap a les elits, sinó també la possibilitat que es detecten antagonismes amb altres col-lectius que no pertanyen a la categoria elit però que tampoc es consideren part integrant de la categoria poble. És ací on se situa la qüestió de la identitat, definida en termes nacionals, culturals i/o religiosos i que s'associa a la concepció nativista que incorporen alguns populismes. Aquest és el plantejament habitual dels partits populistes de dreta radical europeus, que sostenen que el poble corre el risc de perdre la pròpia identitat a causa de la globalització, la immigració i el multiculturalisme (Marzouki, McDonnel i Rey, 2016). Aquests partits consideren els immigrants una amenaça, principalment els musulmans, i els acusen de voler imposar els seus valors i les seues tradicions religioses, i de posar en perill la tradició autòctona — tot i que en molts casos aquesta tradició siga més de tipus cultural que pròpiament religiosa i acostume a estar associada al laïcisme. Per contra, els partits populistes d'esquerres no tenen aquest component identitari i s'inclinen pel laïcisme, l'aconfessionalitat i el multiculturalisme.

L'absència d'una teoria general del populisme no ha impedit que hi haja força consens pel que fa a les raons que n'expliquen l'aparició i creixement, en particular al món occidental recentment. La major part d'explicacions s'han vinculat a les diferents dimensions de la crisi econòmica de 2008 (Shambaugh, 2012). D'acord amb aquest plantejament, el populisme seria, sobretot, una conseqüència del descontentament, de la ràbia i de la frustració generades per la Gran Recessió i les polítiques d'aus- 
teritat. Però també una reacció als efectes perversos que ha tingut la globalització en amplis sectors de la població occidental. En aquest sentit, alguns senten que han perdut l'ocupació i perceben l'arribada massiva d'immigrants com una amenaça mentre altres sectors han experimentat l'estancament de les classes mitjanes i una sensació de privació relativa (Eatwell i Goodwin, 2018). El descontentament derivat d'aquestes circumstàncies hauria sigut capitalitzat pels líders populistes, que haurien apel-lat a la mobilització de la gent comuna en contra d'unes elits polítiques i econòmiques considerades responsables de la situació. En contraposició, el populisme pretendria governar en nom del poble vertader i es presentaria com la resposta al problema de la representació. Des d'aquest punt de vista, el sorgiment del populisme seria també un fenomen de naturalesa política (Roberts, 2015).

En conseqüència, el populisme no seria només una reacció als problemes de naturalesa econòmica i a la percepció de la globalització com una amenaça, sinó que també suposaria un rebuig a un problema polític que s'estaria gestant des de fa temps i que hauria provocat l'erosió dels partits tradicionals. Aquest desgast s'hauria plasmat en el declivi continuat de la militància i les identificacions partidistes, el descens de la participació electoral i l'increment de la volatilitat. Tots aquests fenòmens revelarien les dificultats dels partits, com ha apuntat Mair (2013), per a ser simultàniament responsius, és a dir, permeables a les demandes de l'electorat i responsables com a forces de govern. Així doncs, l'efecte combinat de totes dues crisis, l'econòmica $i$ la política, explicaria el sorgiment dels populismes.

No obstant això, el populisme no és homogeni, sinó que està condicionat per factors de diferents tipus: alguns de naturalesa cultural vinculats a la cultura política de les diferents societats (Norris i Inglehart, 2018), altres de naturalesa institucional com les barreres que poden suposar certs sistemes electorals, i altres de tipus polític com la persistència o no de les fractures polítiques tradicionals $i$, associat a això, el grau d'institucionalització dels par- tits i dels sistemes de partits. D'acord amb aquest últim punt, caldria esperar que la persistència de les fractures polítiques clàssiques, juntament amb l'existència de partits i sistemes de partits altament institucionalitzats, dificultara l'emergència del populisme, mentre que la descomposició de les fractures, junt amb els baixos graus d'institucionalització dels partits i dels sistemes de partits, n'afavorira l'aparició i creixement.

A Espanya, on els trets dels electors no difereixen dels d'altres països on ha arrelat el populisme en particular els trets dels votants de dreta radical (Alonso i Rovira Kaltwasser, 2015) — i on el sistema electoral ha demostrat no ser una barrera per a l'accés de nous partits — que han alterat el sistema de partits i l'han fet molt més obert (Rodríguez-Teruel i Barrio, 2018)—, la solidesa de les fractures polítiques és el principal factor que explicaria la feblesa en l'arrelament del populisme, com sostindrà aquesta anàlisi.

\section{LA LIMITADA PRESÈNCIA DE PARTITS POPULISTES DE DRETA RADICAL}

Després de molts anys de congelació de les fractures polítiques i d'estabilitat del sistema de partits, els primers partits populistes que van alterar el panorama polític a Europa occidental a principis dels anys vuitanta van ser els partits de dreta radical. Aquesta família de partits es caracteritza pel seu nacionalisme i el seu nativisme, de què derivaven tant el seu discurs antiimmigració com la seua oposició al multiculturalisme i el seu rebuig a la globalització i a la integració europea (Mudde, 2007). El populisme ha sigut el corrent polític que més ha crescut a Europa des d'aleshores, però no ho havia fet a Espanya, territori on la insatisfacció política i les actituds cap als immigrants eren bastant homologables a les d'altres països europeus que sí que havien experimentat l'emergència d'aquest tipus de partits.

Plataforma per Catalunya (PxC), una formació que reunia totes les condicions per a ser considerada 
populista de dretes, va ser el primer partit d'aquestes característiques amb una mínima presència institucional. S'oposava a la immigració massiva, a la qual considerava una amenaça tant per a la identitat catalana com per a l'espanyola i per als valors familiars tradicionals. Era molt crític pel que fa a la criminalitat i el terrorisme, i mostrava una preferència pels autòctons en l'assignació de les ajudes, i a més tractava de superar les divisòries polítiques tradicionals. Liderat per Josep Anglada, procedent de l'extrema dreta tradicional, i gràcies a una important presència en els mitjans, va ser capaç de construir un discurs populista modern amb fortes arrels locals (Hernández Carr, 2011) que li va permetre accedir a aquell grau de representació. PxC va comptar amb una certa implantació en municipis catalans amb una alta concentració de població estrangera, però mai va aconseguir representació ni al Parlament de Catalunya ni a les Corts Generals (Casals, 2011; Hernández-Carr, 2012). El febrer de 2019 va aprovar dissoldre's com a partit però continuar la seua activitat com a fundació i assimilar-se a Vox.

L'extrema dreta tradicional vinculada al franquisme també ha sigut molt feble des de la transició i a penes ha tingut presència institucional. Només Fuerza Nueva l'any 1979 va ser capaç de superar el llindar de representació en aconseguir un escó en el Congrés dels Diputats per al seu líder, Blas Piñar. Des d'aleshores, aquesta família política ha sigut extraparlamentària en tots els nivells de govern (Casals, 1998). Factors com la incapacitat per a generar un discurs atractiu, la seua nostàlgia pel passat falangista, els seus coquetejos amb la violència, l'elevat grau de faccionalisme intern i l'absència de lideratge, juntament amb l'aclaparadora preferència dels electors espanyols per les opcions polítiques moderades, expliquen per què l'extrema dreta clàssica a Espanya mai ha sigut rellevant des del restabliment de la democràcia.

El fracàs dels partits de dreta radical, malgrat el seu potencial electoral -és a dir, l'existència d'una certa demanda-, ha sigut atribuit per Alonso i Rovira Kaltwasser (2015) a tres factors vinculats a les dificultats de l'oferta política per a articular-se. En primer lloc, perquè les característiques del sistema electoral no afavoririen l'entrada de xicotetes formacions. En segon terme, perquè l'estructura de les fractures polítiques a Espanya, amb dos clivatges principals - la fractura esquerra-dreta i la fractura centre-perifèria-, es troba molt assentada i dificulta l'aparició de noves línies de conflicte, especialment aquelles amb un component exclusivista o nativista. Motiu pel qual els pocs partits que han tractat de mobilitzar la qüestió migratòria o religiosa han tingut molt poc d'èxit més enllà de l'àmbit local, com il-lustra el cas de PxC. L'últim factor que explicaria l'absència d'una dreta radical a Espanya seria la presència del PP. Aquesta formació, principal partit del centredreta espanyol, i pràcticament l'únic durant molt de temps, hauria optat per una estratègia de competició que li hauria permès ocupar la totalitat de l'espectre ideològic, des del centre-dreta fins a l'extrema dreta, i mobilitzar, d'aquesta manera, els votants potencials de partits populistes de dreta radical.

No obstant això, recentment, Esteban i Martín (2017) han qüestionat aquestes explicacions. Pel que fa al sistema electoral, sostenen que, tot i que tradicionalment no haja afavorit l'entrada de nous partits, la irrupció de Ciudadanos i de Podemos en el cicle electoral 2014-2016 ha posat en dubte aquella explicació clàssica. El sistema de partits, per tant, no seria tant el resultat del sistema electoral —com planteja l'explicació institucional clàssica de matriu duvergeriana- sinó, més aviat, el resultat dels alineaments entorn de les fractures polítiques existents a la societat —com plantegen habitualment les explicacions de tipus sociològic. I quant a l'estructura de les fractures, han argumentat que en altres països on també està present la fractura centre-perifèria, com Itàlia, Bèlgica o el Regne Unit, els partits populistes de dreta han sigut capaços d'accedir al llindar de representació i han estat beneficiats per la connexió entre la qüestió de la immigració i el conflicte centre-perifèria, que emfatitza les preocupacions materials i d'identitat similars, com també ha succeït a Espanya (Pardos 
Prado, 2012). Finalment, Esteban i Martín també han conclòs que, en alguns aspectes, els votants del PP no serien diferents dels votants dels partits populistes de dreta radical a Europa, particularment quant a les valoracions sobre la cultura i la religió de la població d'origen immigrant i en el seu paper com a possibles competidors en el mercat laboral. Diferirien, no obstant això, en alguns aspectes: la tendència que tenen a donar suport al partit governant; el grau menys bel-ligerant de crítica cap als immigrants —en gran mesura per l'origen hispà d'una part important d'aquests, amb els quals comparteixen una mateixa matriu cultural-; una naturalesa més europeista; i finalment, una major inclinació per la llei i l'ordre. Existiria, doncs, un votant del PP susceptible d'identificar-se amb l'electorat de dreta radical europeu que hauria quedat ocult entre l'heterogeneïtat de l'electorat dels populars. El PP, un partit altament institucionalitzat i fins fa poc sense rivals, hauria sigut capaç d'atraure tant els votants potencials de dreta radical com els electors moderats, i hauria exercit una important funció sistèmica com a dic de contenció de la dreta radical. Tot això fins al moment en què, assetjat pels escàndols de corrupció, va perdre el govern l'any 2018 arran de la moció de censura de Pedro Sánchez. A partir d'aquell moment va començar a veure's afectat per la fragmentació de l'espai de la dreta a causa de la irrupció de Ciudadanos i la seua estratègia competitiva i, molt debilitat, es va veure soprés per la irrupció electoral de Vox.

\section{ELS NOUS PARTITS: PODEMOS I CIUDADANOS}

El sorgiment de nous partits a Espanya ha coincidit amb les diferents onades de populisme identificades per Casals (2013). La primera comprendria des del 1989 fins al 2000 i estaria encarnada per José María Ruiz-Mateos, que va aconseguir dos escons en el Parlament Europeu el 1989, i per Jesús Gil, i el seu Grup Independent Liberal (GIL), que va aconseguir les alcaldies de diversos municipis andalusos, entre elles la de Marbella, on el mateix Gil va arribar a ser alcalde, així com la presidència del govern autònom de Ceuta. En tots dos casos, segons assenyala Álvarez Tardío (2017), es tractava d'empresaris que saltaven a la política amb l'ambició de donar veu a un poble que suposadament patia arbitrarietats i corrupció moral i econòmica per part dels partits establerts. Ambdues iniciatives es van aprofitar de l'estructura d'oportunitats que ofereix el sistema multinivell a Espanya - europeu en el cas de Ruiz-Mateos i local en el de Gil- però van tenir dificultats no només per a mantenir-se sinó també per a implantar-se més enllà del nivell en què havien accedit a la representació, motiu pel qual aquesta primera ona no va aconseguir implantar-se. L'últim exponent d'aquesta primera onada populista va ser el també empresari Mario Conde, que va fracassar en el seu intent d'accedir al Congrés dels Diputats l'any 2000. Eixos partits, tots ells molt personalistes i amb un escàs arrelament social, no van ser capaços de fer front a uns partits establerts forts i altament institucionalitzats dins d'un sistema de partits al seu torn molt institucionalitzat i tancat, és a dir, amb una estructura de la competència i unes fractures plenament assentades.

La segona onada es va iniciar el 2003 a Catalunya amb la irrupció a l'àmbit local de Plataforma per Catalunya i de la Candidatura d'Unitat Popular (CUP), una formació independentista d'esquerra radical d'àmbit local. Més tard van aparèixer altres iniciatives que es van articular al voltant de la fractura territorial, com ara Solidaritat Catalana. Però ni Plataforma per Catalunya, com s'ha vist, ni Solidaritat, que va tenir una efímera presència al parlament català (2010-2012), van aconseguir a assentar-se. La CUP, no obstant això, va accedir al Parlament de Catalunya el 2012 i no només ha mantingut una presència constant, sinó que des del 2015 és un partit indispensable per a la governabilitat de Catalunya, cosa que contribueix a explicar la deriva populista que ha experimentat el nacionalisme català en els últims anys (Barrio, Barberà, Rodríguez Teruel, 2018) i que es justifica per l'obertura del sistema de partits i per la primacia de la fractura nacional en detriment de la fractura ideològica (Rodríguez Teruel i Barrio, 2018). 
L'any 2008 va començar la tercera onada. Com s'ha assenyalat, a partir d'aquell any, a Espanya es donen molts dels factors facilitadors del populisme: una profunda crisi econòmica que va provocar nivells d'atur elevats; polítiques d'ajust agressives implementades successivament pels governs socialista i popular que van implicar, en tots dos casos, importants retallades en les polítiques socials i que es van produir de forma paral-lela a un rescat públic d'una part del sistema bancari; finalment, per acabar de rematar-ho, els nombrosos escàndols de corrupció que van afectar els principals partits polítics, sobretot el PP, que governava amb majoria absoluta des del 2011. El desencant ciutadà amb la situació política era tan gran que a partir del 2013, segons els baròmetres del Centre d'Investigacions Sociològiques (CIS), els espanyols consideraven els principals problemes: la situació econòmica, la corrupció, els polítics i els partits. En aquestes circumstàncies cabia esperar l'emergència de formacions populistes de signe diferent, com estava succeint a altres països de l'entorn amb condicions similars. I tot i que, per descomptat, la crisi econòmica i el desprestigi dels vells partits va obrir una finestra d'oportunitat per al sorgiment de nous partits i el seu accés a les institucions (Medina i Correa, 2015; Cordero i Montero, 2015; Orriols i Cordero, 2016; Rodon i Hierro, 2016; Bosch i Durán, 2017), no es pot considerar que a Espanya - encara que tots els partits hagen experimentat un cert contagi populista- haja arrelat el populisme. Com veurem, el pes de la fractura esquerra-dreta i de la fractura nacional ho han dificultat.

Podemos, sorgit a principis de 2014, aspirava en els seus inicis a imposar una lògica populista en el sentit d'Ernesto Laclau (2005). Per aquest motiu, és l'únic dels partits espanyols que s'ha definit a si mateix com un partit populista, motiu pel qual és considerat com a tal per diferents autors (Zarzalejos, 2017; Sanders et al. 2017; Solà i Rendueles, 2017; Ivaldi et. al. 2017). Podemos es proposava superar la dialèctica esquerra-dreta, la fractura més rellevant del sistema polític espanyol, i substituir-la pel dualisme poble-elits propi del populisme
(Rodríguez-Teruel, Barrio i Barberà, 2016; Barrio, Barberà, Rodríguez Teruel, 2018). D'acord amb el clàssic esquema populista, Podemos aspirava a convertir-se en el defensor dels interessos de la gent senzilla enfront dels interessos de l'elit privilegiada, a la qual, emprant el concepte clàssic italià, qualificava de casta, una idea que es va fer molt popular arran de les aparicions televisives d'alguns dels seus principals promotors, com Pablo Iglesias. Molt influït per l'obra La Razón Populista de Laclau (2005), en què es plantejava la idea de la nació com un constructe al servei del poble, Podemos formulava la seua concepció de nació entorn de tres eixos (Torreblanca, 2015: 139). En primer lloc, la democràcia expressada en la idea que les elits no representen el poble i afirmada en el lema «no ens representen» importat del moviment 15-M, del qual Podemos es reclamava continuador. En segon lloc, la sobirania, que adoptava el seu sentit tradicional i es referia a l'autonomia de l'Estat enfront de l'exterior, en clara al·lusió a la influència de les organitzacions supranacionals, particularment la Unió Europea, que va determinar la política econòmica des de l'inici de la crisi. I finalment, la mateixa idea de nació, que materialitzava a través de la garantia dels drets socials. A través d'aquests tres eixos, Podemos pretenia fusionar el component nacional i el component social per a construir un projecte de caràcter transversal capaç de mobilitzar electoralment amplis sectors de la societat, com ja va fer el 15-M. No obstant això, prompte la vocació populista de Podemos es va trobar amb dos límits, tots dos derivats de l'assentament de les fractures tradicionals a Espanya.

D'una banda, la fractura esquerra-dreta i la seua preponderància històrica en la política espanyola. L'aparició d'un altre nou partit, Ciudadanos, considerat per alguns com un Podemos de dretes, com va platejar el famós banquer Josep Oliu, va forçar Podemos a situar-se en l'eix de competència esquerra-dreta en el marc de la nova política. Posteriorment, amb l'objectiu de superar el PSOE, va optar clarament per una estratègia catch-all que, en paraules del propi partit, el posicionés al «centre del tauler polític». Per aquest motiu, més que 
populista, Podemos pot considerar-se un partit d'esquerra radical d'acord amb els criteris establerts per Mudde i March (2005). Radical perquè rebutja l'estructura socioeconòmica subjacent al capitalisme contemporani i els seus valors i pràctiques, i perquè propugna estructures econòmiques i de poder alternatives que impliquen una redistribució important dels recursos de les elits polítiques. I d'esquerres per la seua adhesió als drets econòmics i socials col-lectius. Tot i que el seu radicalisme ha anat matisant-se, particularment arran del seu accés al govern el gener de 2020 .

El programa electoral amb què Podemos va concórrer a les seues primeres eleccions, les europees de 2014, avalava aquest caràcter nítidament radicalesquerrà. Aquell programa va ser elaborat per mitjà d'un procés participatiu obert en què van participar més de 30.000 persones, moltes d'elles procedents de les diferents experiències organitzatives del 15-M. Això explicaria l'adopció per la seua part de plantejaments maximalistes en matèria econòmica, com ara la jubilació als seixanta anys, la negativa al pagament del deute, l'adopció d'una renda bàsica amb caràcter universal o la nacionalització dels sectors clau de l'economia —unes mesures que el mateix partit va considerar inviables posteriorment. Més endavant va encarregar l'elaboració del seu programa econòmic a dos reconeguts experts, Vicenç Navarro (catedràtic de Ciències Polítiques i Socials a la Universitat Pompeu Fabra) i Juan Torres (catedràtic d'Economia a la Universidad de Sevilla), que van situar el partit en l'òrbita de la socialdemocràcia, una estratègia coherent amb l'objectiu de disputar l'espai del PSOE i d'evitar convertir Podemos en una nova versió d'Esquerra Unida, la formació minoritària hereva del partit comunista. Més endavant, la seua aliança amb aquest partit a partir de les eleccions generals de juny de 2016 reforçaria la seua posició en aquest espai ideològic, al mateix temps que consolidaria la seua voluntat de créixer-hi electoralment a costa de la crisi del PSOE. Malgrat ser partits competidors, Podemos va recolzar el maig de 2018 la moció de censura que portà el socialista Pedro Sánchez a la presidència del govern i provocà el desallotjament del PP. Després de la repetició electoral de 2019 es va conformar un govern de coalició inèdit entre tots dos partits, en què Podemos ostenta una vicepresidència, en mans del seu líder Pablo Iglesias, a més de quatre ministeris.

El segon límit a la vocació populista de Podemos està relacionat amb la fractura centre-perifèria. Com s'ha assenyalat abans, la concepció de nació de Podemos està associada a les idees de democràcia i sobirania, aquesta última entesa en sentit clàssic i per tant referida a l'autonomia de l'Estat, que s'associa a la garantia dels drets socials. No obstant això, la complexa realitat nacional a Espanya, així com les perspectives d'implantació i de creixement del propi partit, van dificultar la construcció d'un discurs entorn de qui era el poble, qui s'aspirava a representar i qui integrava la nació. Podemos i els seus aliats a diverses comunitats autònomes, com ara Catalunya, van assumir que Espanya era una nació de nacions amb aspiracions diverses, una assumpció difícilment compatible amb la dialèctica poble-elits quan el demos no n'és només un, sinó diversos, i quan les demandes i aspiracions dels diversos demos són asimètriques. Podemos s'ha enfrontat al repte d'adaptar el seu populisme a les identitats nacionals múltiples existents a Espanya i ho ha fet no sols mostrant-se partidari del reconeixement efectiu de la plurinacionalitat, sinó també donant suport a les aspiracions secessionistes de catalans i bascos. D'ací en deriva el seu compromís amb el dret a l'autodeterminació de Catalunya i el seu suport a la realització d'un referèndum legal, tot i que des del seu accés al govern ha matisat la seua postura. Aquest posicionament no només ha sigut una font de tensions internes, sinó que ha entrat en contradicció amb el pretès enfocament populista del partit i el situa en una posició ambivalent en la fractura centre-perifèria.

No obstant això, cal apuntar que aquestes dificultats per a imposar una lògica populista no han impedit, tal com han apuntat Vallespín i Bascuñán (2017), que Podemos haja conservat alguns elements del populisme, com el llenguatge simplificador, la 
desconfiança cap a la democràcia representativa, la retòrica del poble amb un antagonista definit i el maneig de noves capacitats de comunicació expressives envoltades de racionalitat.

Per la seua banda, Ciudadanos és un partit sorgit l'any 2006 com a resposta a la demanda d'alguns sectors descontents amb l'assumpció de l'agenda nacionalista per part dels partits d'esquerres (Rodríguez Teruel i Barrio, 2016). Malgrat la seua aliança conjuntural amb el partit euròfob Libertas en les eleccions europees de 2009, Ciudadanos no pot ser considerat un partit populista, encara que s'haja vist contagiat pel Zeitgeist populista, com els ha succeït a molts altres partits europeus (Rooduijn et al., 2012). En aquest sentit, Ciudadanos va ser un dels primers partits a Espanya, juntament amb Unión Pueblo y Democracia (UPyD), que ja abans de la crisi econòmica i política denunciava sistemàticament la corrupció dels partits establerts, als quals acusava de tenir complicitats per a protegir-se mútuament, i advocava per la idea de regeneració democràtica. Aquest discurs, tot i que va sorgir a Catalunya i responia a una qüestió específicament catalana, a partir de 2014 va permetre a Ciudadanos (Barrio, 2017b, 2017c) estendre's a la resta d'Espanya i presentar-se al costat de Podemos com a exponent de la nova política. Sense arribar a assumir la dicotomia poble-elit pròpia del populisme, sí que buscava -igual que Podemos- superar la fractura esquerra-dreta i posicionar-se entorn de la divisòria vella-nova política. I encara que va arribar a afirmar, igual que alguns moviments populistes, que no era ni de dretes ni d'esquerres, progressivament es va anar definint-se com un partit de centre. En el seu congrés celebrat el febrer de 2018, en coherència amb la seua adscripció internacional —és membre d'Aliança dels Liberals i Demòcrates per Europa-, va optar per eliminar les referències a la socialdemocràcia del seu ideari i definir-se estrictament com un partit liberal, amb l'expectativa de superar el PP com a conseqüència de la fragmentació de l'espai de dreta. Al mateix temps, va accentuar el seu discurs bel-ligerant cap als nacionalismes perifèrics, en particular el català, fet que afavoreix una competició amb el PP i amb Vox en la seua defensa de la unitat d'Espanya. Tal com alguns esperaven, Ciudadanos passà de ser un partit de centre a convertir-se en el Podemos de dretes. El seu suport al PP en la moció de censura que el va desallotjar del poder i, sobretot, la seua negativa a formar un govern de coalició amb el PSOE després de les eleccions generals d'abril de 2019 — una coalició matemàticament possible i que ideològicament semblava viable-, certificaven aquest canvi, que va ser molt penalitzat, en què el partit va passar dels 57 escons obtinguts en les eleccions generals d'abril als 10 obtinguts en les de novembre.

\section{VOX, UN PARTIT DE DRETA RADICAL NO POPULISTA}

El naixement de Vox, igual que el de Podemos i Ciudadanos, es va produir en el context d'obertura de l'estructura d'oportunitats polítiques que va tenir lloc l'any 2014 i que es va materialitzar en la presentació de candidatures en les eleccions europees d'aquell any. No obstant això, a diferència d'aquells dos partits, Vox no va obtenir representació ni en les eleccions europees ni en cap altra després —amb algunes excepcions a l'àmbit local, com les municipals de 2015 , en què va obtenir uns pocs regidors- fins a les eleccions andaluses de 2018, malgrat haver-s'hi presentat de manera sistemàtica. Les eleccions andaluses van ser les primeres que van tenir lloc des del desallotjament del PP del govern central a conseqüència d'una moció de censura, i també les primeres fora de Catalunya després de la celebració del referèndum d'autodeterminació il-legal de l'1 d'octubre, la declaració d'independència i l'aplicació de l'article 155 de la Constitució espanyola. A partir d'aquell moment, en un context d'amenaça de la integritat territorial de l'Estat i amb un PP molt afeblit, Vox es va posicionar com a principal garant i defensor de la unitat d'Espanya i va experimentar un creixement substancial, tant des del punt de vista organitzatiu com electoral (Barrio, 2019). Després dels bons resultats obtinguts a Andalusia - on a més de traspassar el llindar de representació, va traspassar el de 
rellevància, en convertir-se en força imprescindible per a decantar la majoria-, Vox també aconseguí estar representat a les Corts Generals després de les eleccions d'abril de 2019, amb 24 diputats al Congrés. En algunes comunitats autònomes, com ara la Comunitat de Madrid o Múrcia, i en alguns municipis, com Madrid, també ha tingut accés al llindar de rellevància. Així mateix va obtenir tres diputats en el Parlament Europeu i, després de la repetició de les eleccions generals el novembre de 2019, va aconseguir 57 escons, que el converteixen en la tercera força política a Espanya amb 3.656.979 vots.

Vox és, en primer lloc, un partit nacionalista espanyol que va crèixer gràcies al descontentament polític provocat per la crisi catalana. El seu nacionalisme exacerbat naix d'una preocupació vital per la unitat d'Espanya que es percep amenaçada pel nacionalisme català. Es mostra molt crític amb el desenvolupament del model de descentralització política emanat de la Constitució de 1978 i l'Estat de les Autonomies, al qual considera disfuncional i acusa de generar despeses excessives i de no haver sigut capaç d'integrar els nacionalismes perifèrics. A més, aposta per la transformació d'Espanya en un Estat unitari, descentralitzat administrativament, que reconega la seua pluralitat cultural, lingüística i institucional, però posant l'accent en l'hegemonia del castellà al conjunt del territori. La seua defensa a ultrança de la unitat d'Espanya arriba al punt de plantejar la il-legalització de les organitzacions polítiques independentistes, cosa que suposa —encara que no s'hi referisca explícitament- apostar per un model de democràcia militant que l'ordenament constitucional espanyol no contempla. Proposa un pla integral per a difondre i protegir la identitat nacional fent gala d'un nacionalisme exaltat, i ni tan sols renega de l'apel-latiu despectiu fatxa.

El seu nacionalisme s'acompanya d'un component tradicionalista, nativista i xenòfob, hostil cap allò que defineix com ideologia de gènere. El seu tradicionalisme queda patent en la defensa del model de família tradicional i en la concepció d'aquesta com a institució prèvia a l'Estat, en el rebuig a l'avortament o a les intervencions de canvi de gènere. També enalteix tradicions com els bous o la caça i defensa el cristianisme a ultrança. És profundament contrari a l'islam i planteja tancar las mesquites fonamentalistes a l'hora que exigeix el principi de reciprocitat per a l'obertura de llocs de culte, a més de defensar l'exclusió de l'ensenyament de l'islam a les escoles. Recolza la creació d'una agència d'ajuda a les minories cristianes amenaçades i vincula la immigració estrictament a les necessitats econòmiques i es mostra partidari a la immigració d'origen hispà i es mostra partidari de deportar els immigrants il.legals i els legals que cometen delictes greus i és favorable a impedir que els immigrants il-legals regularitzen la seua situació i puguen accedir a ajudes públiques, així com a suprimir la institució de l'arrelament, que permet accelerar la regularització de les persones en situació irregular. Proposa, igual que Donald Trump per a la frontera entre els Estats Units i Mèxic, la construcció d'un mur entre Ceuta i Melilla i el Marroc, exigint a més que siga sufragat pel mateix Regne Alauita. Acusa el feminisme, com fan altres moviments de dreta radical, de promoure la ideologia de gènere i defensa la supressió dels organismes feministes. També proposa l'eliminació de les quotes i que es derogue la llei de la violència de gènere per considerar que discrimina els homes i es substituisca per una llei de violència intrafamiliar en què tots els membres tinguen el mateix tractament.

La seguretat és una altra de les qüestions prioritàries del partit. En aquest àmbit proposa l'enduriment de les penes i de les condicions dels condemnats i planteja la supressió de l'espai Schengen fins que existisca la garantia europea que no serà utilitzat per a eludir la justícia, en clara al-lusió als polítics catalans fugits a l'estranger. Defensa, a més, la cadena perpètua per als antics integrants de la ja dissolta banda terrorista ETA i la inhabilitació per a tota la vida de les persones que l'hagen secundada o hagen donat suport a les seues diferents expressions polítiques. També recolza el dret d'anar armat i defensar la llar, i fins i tot a condecorar els ciutadans que maten o ferisquen un criminal a la seua casa en legítima defensa. 
D'altra banda, dona suport a la idea de regeneració democràtica i proposa la reforma del sistema electoral. Està a favor d'un menor control dels partits en l'elaboració de les llistes i de la eliminació de les quotes, així com d'endurir el sistema d'incompatibilitats i millorar els mecanismes de control dels càrrecs públics, així com evitar el finançament públic dels partits polítics. De la mateixa manera, planteja la reducció del nombre de municipis i de representants locals, i també pretén restringir el nombre d'assessors polítics. Planteja que la designació dels membres del Consell General del Poder Judicial i del Tribunal Suprem siga per concurs de mèrits i que aquest últim tribunal assumisca les funcions del Tribunal Constitucional, a més de propugnar l'eliminació del jurat popular.

Tots aquests trets situen Vox en l'òrbita de la dreta radical europea, com va evidenciar la seua participació en la cimera de Coblença el gener de 2017, en què també van participar el Front Nacional francés, Alternativa per a Alemanya o el Partit Liberal austríac, amb l'objectiu de coordinar estratègies a escala europea. No obstant això, no és un partit ferventment antieuropeu ni essencialment populista. De fet, després de les eleccions europees va ingressar en el Grup de Conservadors i Reformistes Europeus, fet amb el qual es va distanciar de l'intent, avalat per Steve Bannon, de formar un grup unificat de dreta radical i euroescèptic sota la direcció de Marine Le Pen i Matteo Salvini (Barrio, en premsa).

La seua posició pel que fa a la Unió Europea és ambivalent. El Manifest Fundacional no contenia cap referència - ni positiva ni negativa - a Europa, de la qual cosa es deriva que no és una qüestió central per al partit. El seu programa per a les eleccions europees de 2014 contenia una aspiració genèrica a la millora del funcionament institucional i de les polítiques europees, així com a l'aprofundiment democràtic. A partir de 2015, coincidint amb la crisi dels refugiats, Vox va mostrar la seua predilecció per les posicions del Grup de Visegrád en matèria migratòria i va començar a decantar-se per un funcionament més intergovernamental de la Unió Europea i per un rebuig més explícit al supranacionalisme i a qualsevol mena de participació subestatal en les decisions europees. No obstant això, no qüestiona la pertinença d'Espanya a la UE, sinó que advoca per transformar-la des de dins, com van defensar la majoria de partits de dreta radical de cara a les eleccions de 2019. En el seu programa per a aquests comicis va posar èmfasis en la garantia de la sobirania dels estats, en la seua integritat territorial i en el manteniment de la singularitat cultural europea de matriu cristiana enfront de l'amenaça estrangera, així com en un enduriment de la política migratòria i d'asil i la millora de la política de seguretat i defensa.

No obstant això, a Vox li manca el component populista que sol acompanyar la dreta radical. Certament impugna els partits establerts i apel-la a la regeneració democràtica i a la necessitat de dur a terme reformes institucionals davant la degradació que, al seu judici, ha provocat l'estat de partits, especialment arran dels escàndols de corrupció que afecten les grans formacions. Però no compleix amb el conjunt de requisits que la literatura acadèmica sol identificar amb el populisme, en particular els que contempla la definició de Mudde (2004). No considera que existisquen dos grups homogenis, el poble virtuós i l'elit corrupta, ni emfatitza l'existència de relacions antagòniques entre ells. No concep la política com el resultat de l'antagonisme entre tots dos grups ni mostra predilecció per la democràcia directa per damunt d'altres instruments de la democràcia liberal. Ni tan sols vincula al poble l'èmfasi en la idea de sobirania, sinó a Espanya. Si bé és cert que no escapa a un cert contagi populista, com la majoria de partits en el món occidental —en particular pel que fa a la voluntat moralitzadora de la vida política一, no es pot considerar estrictament populista.

Vox és un cas singular de partit de dreta radical no populista, fet que permet mantenir a Espanya en el terreny de l'excepcionalitat quant a l'escàs arrelament del populisme. El seu auge no s'explica per la crisi econòmica i política de 2008 —encara que sí el seu naixement- sinó per la crisi política que 
va desencadenar l'amenaça secessionista catalana a la fi de 2017 i per la crisi del PP a partir de la primavera de 2018. Vox és un partit nacionalista espanyol situat en l'extrema dreta que creix no pel seu populisme sinó per la seua posició en les dues principals fractures de la vida política espanyola: fractures plenament vigents i que en l'últim cicle electoral, com ja va succeir durant la Segona República, han tendit a superposar-se i a reforçar-se mútuament.

\section{CONSIDERACIONS FINALS}

A Espanya, on recentment s'ha donat una combinació dels factors que acostumen a afavorir l'emergència del populisme - una crisi econòmica i una crisi de naturalesa política一, el populisme no hi ha arrelat, fet que la converteix en una rara excepció en l'àmbit de les democràcies occidentals.

Històricament, els partits populistes de dreta radical han tingut una implantació molt escassa i limitada a l'àmbit local. El rebuig a l'herència franquista, la moderació ideològica de l'electorat, les dificultats d'accedir a les institucions per un sistema electoral i, sobretot, la presència del $\mathrm{PP}$, un partit que ha sigut capaç d'atraure electors que poden ser qualificats de populistes radicals, n'ha limitat el creixement potencial fins fa molt poc.

Els partits de naturalesa populista sorgits en diferents onades han tingut dificultats per a implantar-se a causa de l'elevada institucionalització dels partits i del sistema de partits. Entre els nous partits sorgits a conseqüència de la crisi, Podemos, un partit que s'ha autodefinit com a populista d'acord amb la concepció de Laclau, no ha pogut imposar la seua lògica i ha optat per adaptar-se a l'estructura de la competència política a Espanya per tal de competir amb el PSOE en l'espai d'esquerres.

D'igual manera, l'existència d'una fractura nacional important dificulta la seua concepció populista per l'existència de diversos demos. Ciudadanos, per la seua banda, tot i que comparteix amb molts dels partits polítics populistes la seua crítica als partits establerts i la seua voluntat regeneradora, no emfatitza en cap altre aspecte que permeta catalogar-lo com a populista, i més aviat ha tendit a remarcar la seua posició com a partit liberal en la fractura esquerra-dreta i la seua posició contrària als nacionalismes perifèrics en la fractura nacional.

Finalment, la recent irrupció de Vox obliga a matisar la idea fins fa poc acceptada que Espanya era immune a la dreta radical. No obstant això, el seu creixement no s'explica a conseqüència de la crisi econòmica o política, sinó que sembla ser fruit de la crisi territorial desencadenada arran de l'intent de secessió de l'independentisme català i de l'oportunitat que ofereix la fragmentació de l'espai de dretes, així com per la creixent feblesa del PP. Comparteix amb la família de partits de dreta radical el nacionalisme, el tradicionalisme, el nativisme i el rebuig al feminisme, però li manca el component populista. Ni té una visió dualista de la societat ni contraposa el poble a les elits. Tampoc es presenta com la veu del poble, ni mostra preferència per instruments de democràcia directa en detriment de la democràcia representativa, per la qual cosa constitueix un exemple estrany de partit de dreta radical no populista. Emfatitza sobretot el nacionalisme i la seua defensa de la unitat d'Espanya, posant el focus en una de les fractures clàssiques de la política espanyola.

Malgrat la profunda transformació que ha experimentat el sistema de partits recentment a Espanya, un dels factors que sol afavorir l'auge i la consolidació del populisme, la persistència i la tendència a la superposició de les fractures polítiques tradicionals -l'esquerra-dreta i la nacional- han dificultat la implantació del populisme, definit segons Mudde (2004) com el moviment segons el qual la societat està dividida en dos grups antagònics i homogenis -el poble pur enfront d'una elit política- i aspira a que la política siga l'expressió del desig del poble. 


\section{REFERÈNCIES BIBLIOGRÀFIOUES}

Alonso, S. i Rovira Kaltwasser, C. (2015). Spain: No Country for the Populist Radical Right?, South European Society and Politics, 20(5), 21-45.

Álvarez Tardío, M. (2017). El populismo en la democracia española: De Gil a Podemos. En A. Rivero, J. Zarzalejos, J. i J. del Palacio (coord.), Geografía del Populismo (p. 260-271). Madrid: Tecnos.

Barrio, A. (2017a). El populismo y la excepcionalidad española. Quaderni di Diritto e Politica Ecclesiastica, 2, 263-276.

Barrio, A. (2017b). Ciutadans: De la irrelevancia a liderar la oposición. En J. Marcet i L. Medina (ed.), La política del proceso: Actores y elecciones (2010-2016) (p. 125-137). Barcelona: Institut de Ciències Polítiques i Socials.

Barrio, A. (2017c). El partido anticatalanista que hizo las Españas. En E. Forti, A. González Vilata i E. Ucelay-Da Cal (ed.), El Proceso separatista en Cataluña: Análisis de un pasado reciente (2006-2017) (p. 225-243). Granada: Comares.

Barrio, A. (2019). "Vox, la fin de de l'exception espagnole" Fondation pour l'Innovation Politique (Fondapol).

Barrio, A. (en premsa). Vox y la irrupción de la derecha radical en España. En O. Barberà (ed.), La derecha radical. València: Fundació Nexe.

Barrio, A., Barberà, O. i Rodríguez-Teruel, J. (2018). Spain Steals from Us!' The 'Populist Drift' of Catalan Regionalism. Comparative European Politics, 16(6) 993-1011.

Bosch, A. i Durán, I. (2017). How Does Economic Crisis Impel Emerging Parties on the Road to Elections? The Case of the Spanish Podemos and Ciudadanos. Party Politics, 25(2), 257-267. DOI: 10.1177/1354068817710223

Casals, X. (1998). La tentación neofascista en España. Barcelona: Plaza \& Janés.

Casals, X. (2011). Cataluña: ¿Nuevos partidos para viejas inquietudes? En J. Marcet i X. Casals, Partidos y elecciones en la Cataluña del siglo XXI (Р. 99-133). Barcelona: Institut de Ciències Polítiques i Socials.

Casals, X. (2013). El pueblo contra el parlamento. Barcelona: Pasado y Presente.

Canovan, M. (1982). Two Strategies for the Study of Populism. Political Studies, 30(4) 544-552.

Cordero, G. i Montero, J. R. (2015). Against Bipartyism, towards Dealignment? The 2014 European Election in Spain. South European Society and Politics, 20(3) 357-379.

Eatwell, R. i Goodwin, M. (2018). National Populism: The Revolt Against Liberal Democracy. Londres: Pelican Book.

Esteban, I. i Martín, I. (maig 2017). Is There a Hidden Populist Right in Spain? Congrés celebrat a la Universitat Carolina de Praga, Third Prague Populism Conference «Current Populism in Europe and the Role of the Media». Panel «Left and Right Populism in the Iberian Peninsula».

Hernández-Carr, A. (2011). ¿La hora del populismo? Elementos para comprender el «éxito» electoral de Plataforma per Catalunya. Revista de Estudios Políticos, (153) 47-74.

Hernández-Carr, A. (2012). La irrupción de la nueva extrema derecha en España: Un análisis de la trayectoria, estrategia política flybase electoral de Plataforma per Catalunya (Tesi doctoral). Universitat Autònoma de Barcelona, Bellaterra, Barcelona. Recuperat de http://www.tesisenred.net/handle/10803/96408

Ivaldi, G., Lanzone, M. E. i Woods, D. (2017). Varieties of Populism across a Left-Right Spectrum: The Case of the Front National, the Northern League, Podemos and Five Star Movement. Swiss Political Science Review, 23(4), 354-376

Kriesi, H. i Pappas, T. S. (2015). European Populism in the Shadow of the Great Recession. Colchester: European Consortium for Political Research.

Laclau, E. (2005). La razón populista. Ciutat de Mèxic: Fondo de Cultura Económica.

Mair, P. (2013). Ruling the Void. Londres: Verso.

Marzouki, N., McDonnel, D. i Rey, O. (ed) (2016). Saving the People. Londres: Hurst \& Co.

Medina, I. i Corea, P. (2016). The 2015 Spanish Election: The Times They Are a' Changing. Regional \& Federal Studies, 26(3), 407-417.

Moffit, B. i Tormey. S. (2014). Rethinking Populism: Potitics, Mediatisation and Political Style. Political Studies, 62(2), 381- 397.

Mudde, C. (2004). The Populist Zeitgeist. Goverment and Opposition 39(4) 542-563.

Mudde, C. (2007). Populist Radical Right Parties in Europe. Cambridge: Cambridge University Press.

Mudde, C. i March, L. (2005). What's Left of the Radical Left? The European Radical Left Since 1989: Decline and Mutation. Comparative European Politics, 3(1), 29-49. 
Norris, P. i Inglehart, R. (2018). Cultural Backlash and the Rise of Populism: Trump, Brexit and the Rise of Authoritarianism Populism. Nova York: Cambridge University Press.

Orriols, L. i Cordero, G. (2016). The Breakdown of the Spanish Two-party System: The Upsurge of Podemos and Ciudadanos in the 2015 General Election. South European Society and Politics, 21(4), 469-492. DOI: 10.1080/13608746.2016.1198454

Pappas, T. S. (2014). Populist Democracies: Post-Authoritarian Greece and Post-Communist Hungary. Government and Opposition, 49(1), 1-23.

Pardos-Prado, S. (2012). The Electoral Effect of Immigration Preferences and the Centre-Periphery Cleavage in Spain. South European Society and Politics, 17(3), 503-518.

Roberts, K. M. (2015). Populism, Political Mobilizations, and Crises of Political Representation. En C. de la Torre (ed.), The Promise and Perils of Populism: Global Perspectives (p. 140-158). Lexington: The University Press of Kentucky.

Rodon, T. i Hierro, M. J. (2016). Podemos and Ciudadanos Shake up the Spanish Party System: The 2015 Local and Regional Elections. South European Society and Politics, 21(3), 339-357.

Rodríguez-Teruel, J. i Barrio, A. ( 2016). Going National: Ciudadanos from Catalonia to Spain. South European Society and Politics, 21(4), 587-607.

Rodríguez-Teruel, J., Barrio, A. i Barberà, O. (2016). Fast and Furious: Podemos' Quest for Power in Multi-level Spain. South European Society and Politics, 21(4), 561-585.

Rodríguez-Teruel, J. i Barrio, A. (2018). El sistema de partidos multinivel en España. En J. M. Reniu (ed.), Sistema político español (p. 347-361). Barcelona: Huygens.

Solà, J. i Rendueles, C. (2017). Podemos, the Upheaval of Spanish Politics and the Challenge of Populism. Journal of Contemporary European Studies, 26(1), 99-116. DOI: 10.1080/14782804.2017.1304899

Rooduijn, M., Lang, S. L. i Van der Brug. W. (2012). A Populist Zeitgeist? Programatic Contagion by Populist Parties in Western Europe. Party Politics, 20(4), 563-575.

Sanders, K., Molina Hurtado, M. J. i Zoragastua, J. (2017). Populism and Exclusionary Narratives: The 'other' in Podemos 2014 European Union Election Campaign. European Journal of Communication, 32(6), 552-567.

Shambaugh, J. C. (2012). The Euro's Three Crises. Brookings Papers on Economic Activity, 43(1), 157-231.

Stanley, B. (2008). The Thin Ideology of Populism. Journal of Political Ideologies, 13(1), 95-110.

Torreblanca, I. (2015). Asaltar los cielos. Barcelona: Debate.

Vallespín, F. i Martínez-Bascuñán, M. (2017). Populismos. Madrid: Alianza Editorial.

Zakaria, F. (1997). The Rise of Illiberal Democracy. Foreign Affairs, 76(6), 22-43.

Zarzalejos, J. (2017). Nacionalismo y populismo en España. En A. Rivero, J. Zarzalejos i J. del Palacio (coord.), Geografía del populismo. Madrid: Tecnos.

\section{NOTA BIOGRÀFICA}

Astrid Barrio és professora de Ciència Política a la Universitat de València. És doctora en Ciència Política per la Universitat Autònoma de Barcelona i DEA per l'Institut d'Études Politiques de París (Sciences-Po). El seu àmbit d'investigació són els partits, les elits polítiques, els sistemes de partits i el nacionalisme. És autora de nombrosos capítols de diversos llibres i ha publicat articles en revistes com Ethnic and Racial Studies, Revista Española de Ciencia Política, Revista Española de Investigaciones Sociológicas, Comparative European Politics, South European Society and Politics o Mediterranean Politics, entre d'altres. Escriu regularment en diferents mitjans com El Periódico o La Vanguardia i és analista habitual en TV3, Catalunya Ràdio, La Ser, RAC1 i RTVE. Així mateix, és fundadora d'Agenda Política i de la revista Política \& Prosa. Tota la seua producció acadèmica pot consultar-se en: https://uv.academia.edu/astridbarrio. 